\title{
Intraoperative Breast Injury
}

National Cancer Institute

\section{Source}

National Cancer Institute. Intraoperative Breast Injury. NCI Thesaurus. Code C78376.

Damage to the breast parenchyma during a surgical procedure. 